\title{
Based-Catalyzed Stereoselective Thiosulfonylation of Ynones
}

Jinyun Luo, Muze Lin, Guangfen Du, * Zhihua Cai, Lin He*

Key Laboratory for Green Processing of Chemical Engineering of Xinjiang Bingtuan, School of Chemistry and Chemical Engineering, Shihezi University, Xinjiang Uygur Autonomous Region, 832000, China.

Email: duguangfen@shzu.edu.cn; helin@shzu.edu.cn

Abstract:

The first catalytic vicinal thiosulfonylation of ynones has been developed. Under the catalysis of $1-10 \quad \mathrm{~mol}^{\%} \quad \mathrm{Cs}_{2} \mathrm{CO}_{3}$, various thiosulfonates underwent Michael addition/nucleophilic substitution tandem reaction with different ynones to form $\mathrm{C}-\mathrm{SO}_{2}$ and $\mathrm{C}-\mathrm{S}$ bonds simultaneously and produce multifunctional vinyl sulfones in high yields and excellent $E$-selectivity.

\section{Introduction}

Organosulfur compounds are widely used in medicinal and biochemistry, organic synthesis and material science. ${ }^{1}$ Thus, the development of efficient method for the construction of C-S bond and the installation of sulfurcontaining functional groups into organic molecules are topics of continuous interest. Among different sulfur-containing compounds, vinyl sulfones often serve as the critical structural motifs in numerous pharmaceuticals and biologically active compounds. ${ }^{2}$ Given the great significance, considerable efforts have been exerted to develop efficient methods for the synthesis of these important frameworks. ${ }^{3}$ Except for the 
classic Knoevenagel condensation reaction, ${ }^{4}$ Horner-Wadsworth-Emmons olefination ${ }^{5}$ and vinyl sulfides oxidation reactions, ${ }^{6}$ atom transfer radical addition (ATRA) ${ }^{7}$ has emerged as a powerful strategy for the synthesis of vinylsulfone derivatives. A number of difunctionalization of alkynes, including halosulfonylation, ${ }^{8}$ selenosulfonylation, ${ }^{9}$ aminosulfonylation, ${ }^{10}$ disulfonylation, ${ }^{11}$ thiocyanatosulfonylation, ${ }^{12}$ carbosulfonylation ${ }^{13}$ and carboxysulfonylation, ${ }^{14}$ have been developed through ATRA reactions. In sharp contrast, thiosulfonylation of alkynes has only rarely investigated, which allows concomitant formation of $\mathrm{C}-\mathrm{SO}_{2}$ and $\mathrm{C}-\mathrm{S}$ bond in one step. Recently, $\mathrm{Xu}$ and coworkers ${ }^{15}$ reported an elegant dual gold/photoredoxcocatalyzed ATRA to alkynes, which provides a novel protocel for the synthesis of thio-functionalized vinylsulfones. Interestingly, using Eosin $\mathrm{Y}$ as photocatalyst, Jia and coworkers ${ }^{16}$ realized a similar thiosulfonylation of alkynes under metal-free conditions, but with reversed regioselectivity. Very recently, Reddy and coworkers ${ }^{17}$ reported that the same products can also be obtained through a new radical-involved vicinal thiosulfonylation of 1,1-dibromo-1-alkynes. However, these aforementioned radical reactions are not suitable for thiosulfonylation of ynones due to the dramatically reduced stability of $\alpha$-ketone alkenyl radical intermediate as compared to alkenyl radical.

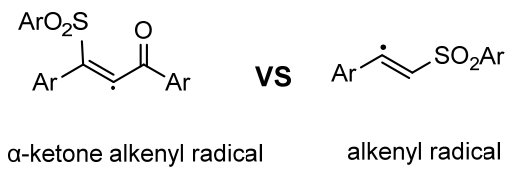


Scheme $1 \alpha$-ketone alkenyl radical and alkenyl radical

To the best of our knowledge, there is no method for vicinal thiosulfonylation of ynones has been disclosed to date. Therefore, the development of novel and mechanically different method for vicinal thiosulfonylation of ynones is highly desirable. As part of our continuous research on C-S bond formation reactions, ${ }^{18}$ we envisaged that a base can catalyze the Michael-addition/nucleophilic substitution tandem reaction of ynones and thiosulfonates to produce multifunctional vinylsulfones through a novel non-radical process. Herein, we would like to report this result.

\section{Results and discussion}

At outset, we commenced our study with ynone 1a and thiosulfonate $\mathbf{2 a}$ as the model substrates. To our delight, in the presence of $10 \mathrm{~mol} \% \mathrm{DBU}$, the vicinal thiosulfonylation reaction proceeded smoothly in THF at room temperature to produce the desired product $3 \mathbf{3}$ in $87 \%$ yield (Table 1, entry 1). Encouraged by this success, several other common bases were then examined. TBD and DBN catalyzed the difunctionalization in high yield (Table 1, entries 2 and 3). Triethylamine, the Hunig's base, DABCO and $\mathrm{Ph}_{3} \mathrm{P}$ cannot catalyze the reaction (Table 1 , entries $4-7$ ). ${ }^{t} \mathrm{BuOK}$ catalyzed the reaction in modest yield (Table 1, entry 8). Inorganic bases, such as $\mathrm{NaOH}, \mathrm{Na}_{2} \mathrm{CO}_{3}$ and $\mathrm{K}_{2} \mathrm{CO}_{3}$ are inefficient for the reaction (Table 1, entries 9-11). Interestingly, $\mathrm{Cs}_{2} \mathrm{CO}_{3}$ catalyzed the reaction in high yield (Table 1 , 
entry 12). A brief evaluation of the reaction media indicated that acetonitrile was the best choice with respect to the yield (Table 1, entries 13-17) Reducing the amount of 1a to 1.2 equivalents led to slightly decreased reaction yield (Table 1, entry 18). Interestingly, reducing the catalyst loading to $5 \mathrm{~mol} \%$, excellent yield and stereoselectivity were maintained (Table 1, entry 19). However, further reducing the catalyst loading to $1 \mathrm{~mol} \%$ resulted in decreased reaction yield (Table 1 , entry 20). Finally, the control experiment showed that in the absence of a base, no desired product was formed (Table 1, entry 21).

Table 1 Optimization of reaction conditions ${ }^{\text {a }}$

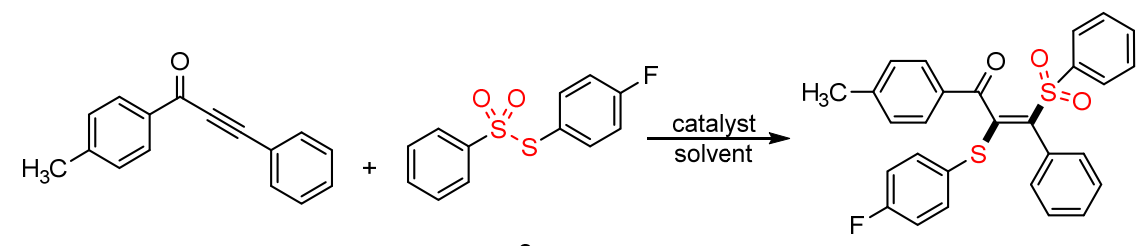

$1 a$

$2 a$

$3 a$

\begin{tabular}{|c|c|c|c|c|c|}
\hline Entry & base & solvent & Time/h & $\mathrm{E} / \mathrm{Z}^{\mathrm{c}}$ & Yield $(\%)^{b}$ \\
\hline 1 & DBU & THF & 7 & $>25: 1$ & 87 \\
\hline 2 & TBD & THF & 7 & $>25: 1$ & 97 \\
\hline 3 & $\mathrm{DBN}$ & THF & 7 & $>25: 1$ & 76 \\
\hline 4 & $\mathrm{Et}_{3} \mathrm{~N}$ & THF & 7 & $>25: 1$ & $\mathrm{nr}$ \\
\hline 5 & DIPEA & THF & 7 & $>25: 1$ & $\mathrm{nr}$ \\
\hline 6 & DABCO & THF & 7 & $>25: 1$ & $\mathrm{nr}$ \\
\hline 7 & $\mathrm{PPh}_{3}$ & THF & 7 & $>25: 1$ & $\mathrm{nr}$ \\
\hline 8 & ${ }^{t} \mathrm{BuOK}$ & THF & 7 & $>25: 1$ & 34 \\
\hline 9 & $\mathrm{NaOH}$ & THF & 7 & $>25: 1$ & $\mathrm{nr}$ \\
\hline 10 & $\mathrm{Na}_{2} \mathrm{CO}_{3}$ & THF & 7 & $>25: 1$ & $\mathrm{nr}$ \\
\hline 11 & $\mathrm{~K}_{2} \mathrm{CO}_{3}$ & THF & 7 & $>25: 1$ & $\mathrm{nr}$ \\
\hline 12 & $\mathrm{Cs}_{2} \mathrm{CO}_{3}$ & THF & 7 & $>25: 1$ & 93 \\
\hline 13 & $\mathrm{Cs}_{2} \mathrm{CO}_{3}$ & DCM & 7 & $>25: 1$ & 22 \\
\hline 14 & $\mathrm{Cs}_{2} \mathrm{CO}_{3}$ & DCE & 7 & $>25: 1$ & 42 \\
\hline 15 & $\mathrm{Cs}_{2} \mathrm{CO}_{3}$ & $\mathrm{MeOH}$ & 7 & $>25: 1$ & 5 \\
\hline
\end{tabular}




\begin{tabular}{cccccc}
16 & $\mathrm{Cs}_{2} \mathrm{CO}_{3}$ & $\mathrm{CH}_{3} \mathrm{CN}$ & 7 & $>25: 1$ & 98 \\
17 & $\mathrm{Cs}_{2} \mathrm{CO}_{3}$ & toluene & 7 & $>25: 1$ & 6 \\
$18^{\mathrm{d}}$ & $\mathrm{Cs}_{2} \mathrm{CO}_{3}$ & $\mathrm{CH}_{3} \mathrm{CN}$ & 7 & $>25: 1$ & 95 \\
$19^{\mathrm{e}}$ & $\mathrm{Cs}_{2} \mathrm{CO}_{3}$ & $\mathrm{CH}_{3} \mathrm{CN}$ & 7 & $>25: 1$ & 98 \\
$20^{\mathrm{f}}$ & $\mathrm{Cs}_{2} \mathrm{CO}_{3}$ & $\mathrm{CH}_{3} \mathrm{CN}$ & 8 & $>25: 1$ & 85 \\
21 & $/$ & $\mathrm{THF}$ & 24 & $/$ & $\mathrm{nr}$ \\
\hline
\end{tabular}

${ }^{a}$ Reaction conditions: 1a $(0.6 \mathrm{mmol}), 2 \mathrm{a}(0.4 \mathrm{mmol})$, base $(10 \mathrm{~mol} \%), \mathrm{CH}_{3} \mathrm{CN} \quad(4.0 \mathrm{~mL}), 8 \mathrm{~h}, \mathrm{rt}$; ${ }^{b}$ Isolated yield; ${ }^{c}$ Ratio of $E / Z$ isomers was determined by ${ }^{1} \mathrm{H}$ NMR analysis of the crude products; ${ }^{d} \mathbf{1 a}(0.48 \mathrm{mmol}), 2 \mathrm{a}(0.4 \mathrm{mmol}) ;{ }^{e} \mathrm{Cs}_{2} \mathrm{CO}_{3}(5 \mathrm{~mol} \%) ;{ }^{f} \mathrm{Cs}_{2} \mathrm{CO}_{3}(1 \mathrm{~mol} \%)$.

With the optimal reaction conditions in hand, we first examined the substrate scope of ynones, with the results summarized in Table 2. A variety of ynones with substituents on the aromatic rings underwent the thiosulfonylation efficiently to give the desired vinyl sulfones in high yield and excellent regio- and stereoselectivity (3a-3q). In addition, different positions and electronic properties have no apparent impact on the reaction yield and selectivity (3r-3x). The bulky naphthyl derived ynones $\mathbf{1 y}$ and $\mathbf{1 z}$ participated in the reaction to afford the corresponding products $\mathbf{3 y}$ and $\mathbf{3 z}$ in $98 \%$ and $88 \%$ yields, respectively. Heteroaryl substituted ynones were proven to be very good reactants for the reaction, furnishing the corresponding produces in excellent yield (3aa-3ac). Gratifyingly, different alkyl-substituted ynones also performed very well, giving the desired products in high yield and excellent E-selectivity (3ad-3ai).

Table 2. Substrate scope of ynones ${ }^{\text {a }}$ 


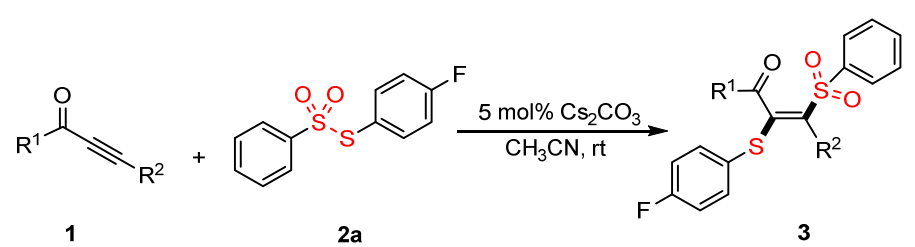

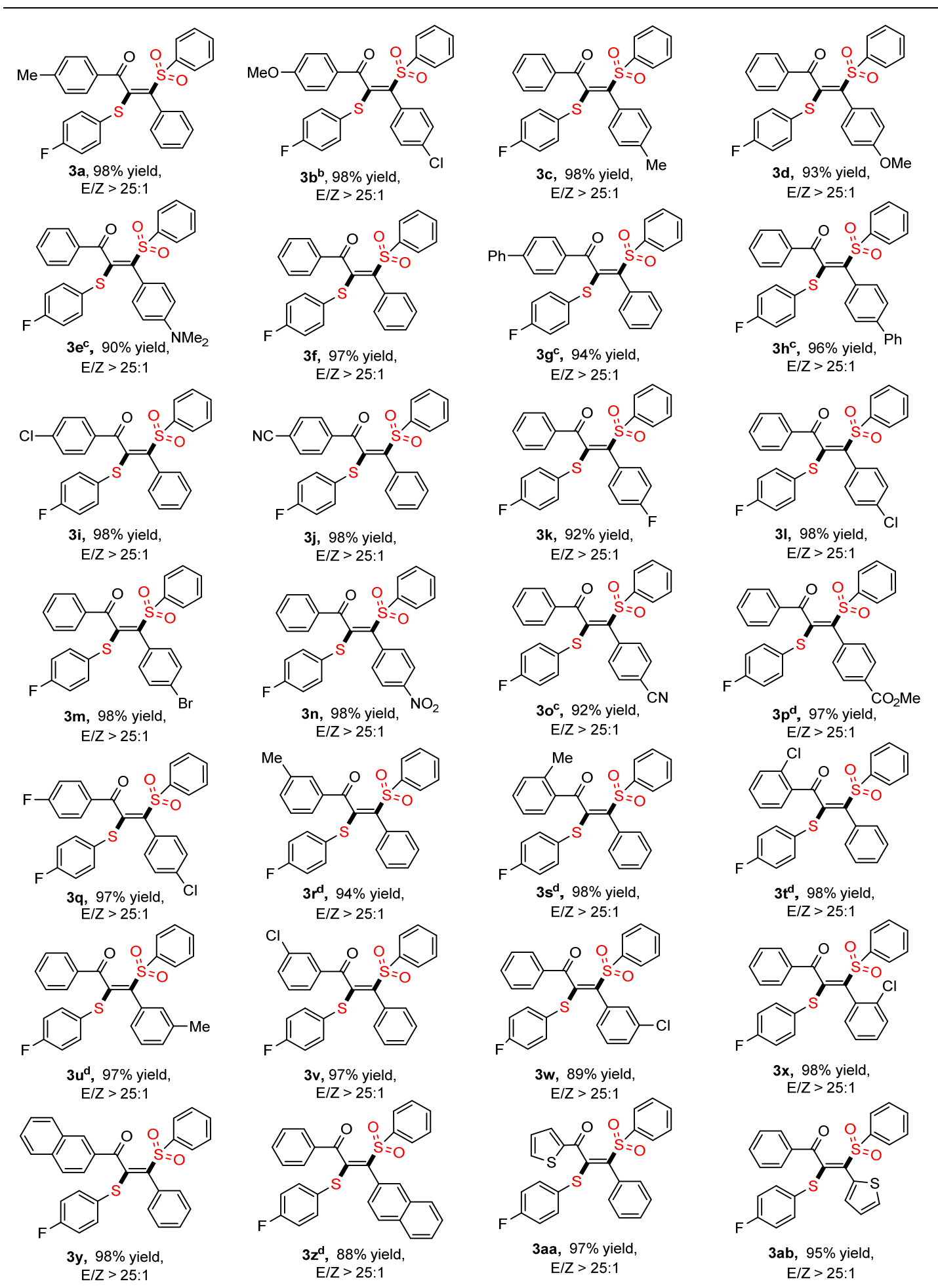



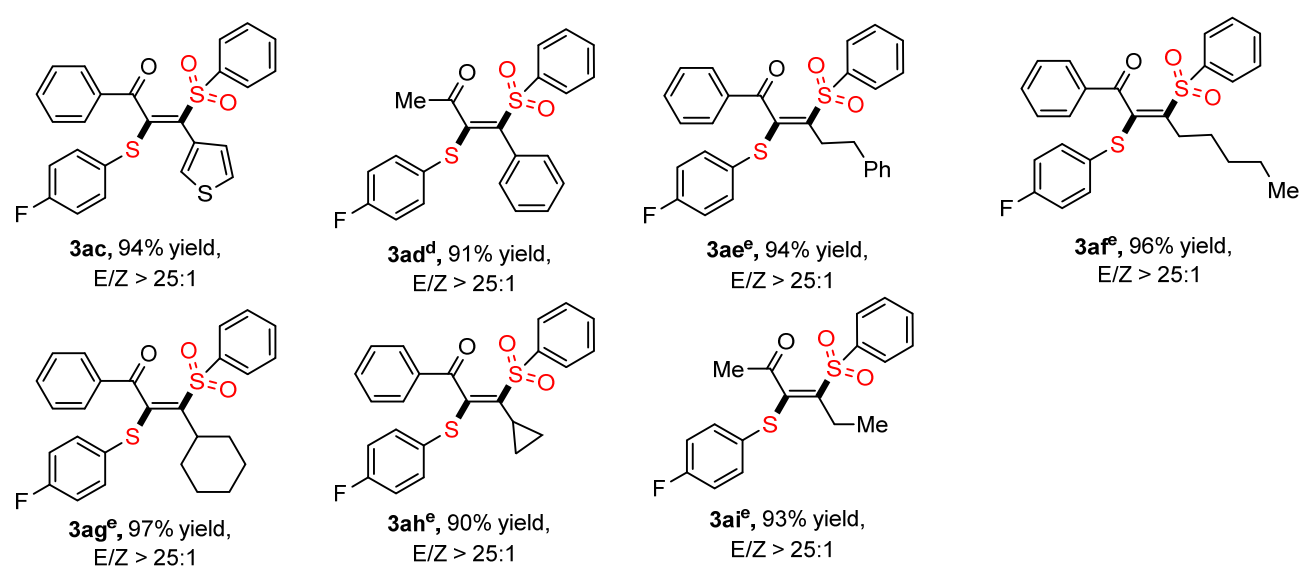

${ }^{a}$ Reaction conditions: 1a $(0.6 \mathrm{mmol}), 2 \mathbf{a}(0.4 \mathrm{mmol}), \mathrm{Cs}_{2} \mathrm{CO}_{3}(5 \mathrm{~mol} \%), \mathrm{CH}_{3} \mathrm{CN}(4.0 \mathrm{~mL}), 8 \mathrm{~h}, \mathrm{rt}$; isolated yield, ratio of $E / Z$ isomers was determined by ${ }^{1} \mathrm{H}$ NMR analysis of the crude products; ${ }^{b}$ $\mathrm{Cs}_{2} \mathrm{CO}_{3}(1 \mathrm{~mol} \%) ;{ }^{c} \mathrm{Cs}_{2} \mathrm{CO}_{3}(2 \mathrm{~mol} \%) ;{ }^{d} \mathrm{Cs}_{2} \mathrm{CO}_{3}(10 \mathrm{~mol} \%) ;{ }^{e} \mathrm{Cs}_{2} \mathrm{CO}_{3}(20 \mathrm{~mol} \%)$.

We next investigated the substrate scope of thiosulfonates in this transformation. Both symmetrical and unsymmetrical thiosulfonates smoothly underwent the reaction, affording the corresponding thiofunctionalized vinylsulfones in high yields and excellent regioselectivity (Table 3). Substrates bearing electron-donating, -withdrawing and neutralsubstituents coupled with ynones to produce the desired products in excellent yields (3aj-3ap). Different positions of the substituents have no obvious influence on the reaction yield and selectivity (3aq-3as). The bulky naphthyl-derived thiosulfonate $2 \mathbf{l}$ reacted efficiently with ynone $1 \mathrm{x}$ to furnish 3at in high yield. Heteroaryl-derived thiosulfonate $\mathbf{2 m}$ underwent the reaction to provide 3au in 95\% yield. Notably, alkyl thiosulfonates performed smoothly to afford the corresponding products in high yields (3av-3ax). The configuration of 3ap was unambiguously determined by X-ray crystallography analysis. ${ }^{19}$ 
Table 3. Substrate scope of thiosulfonates ${ }^{\text {a }}$

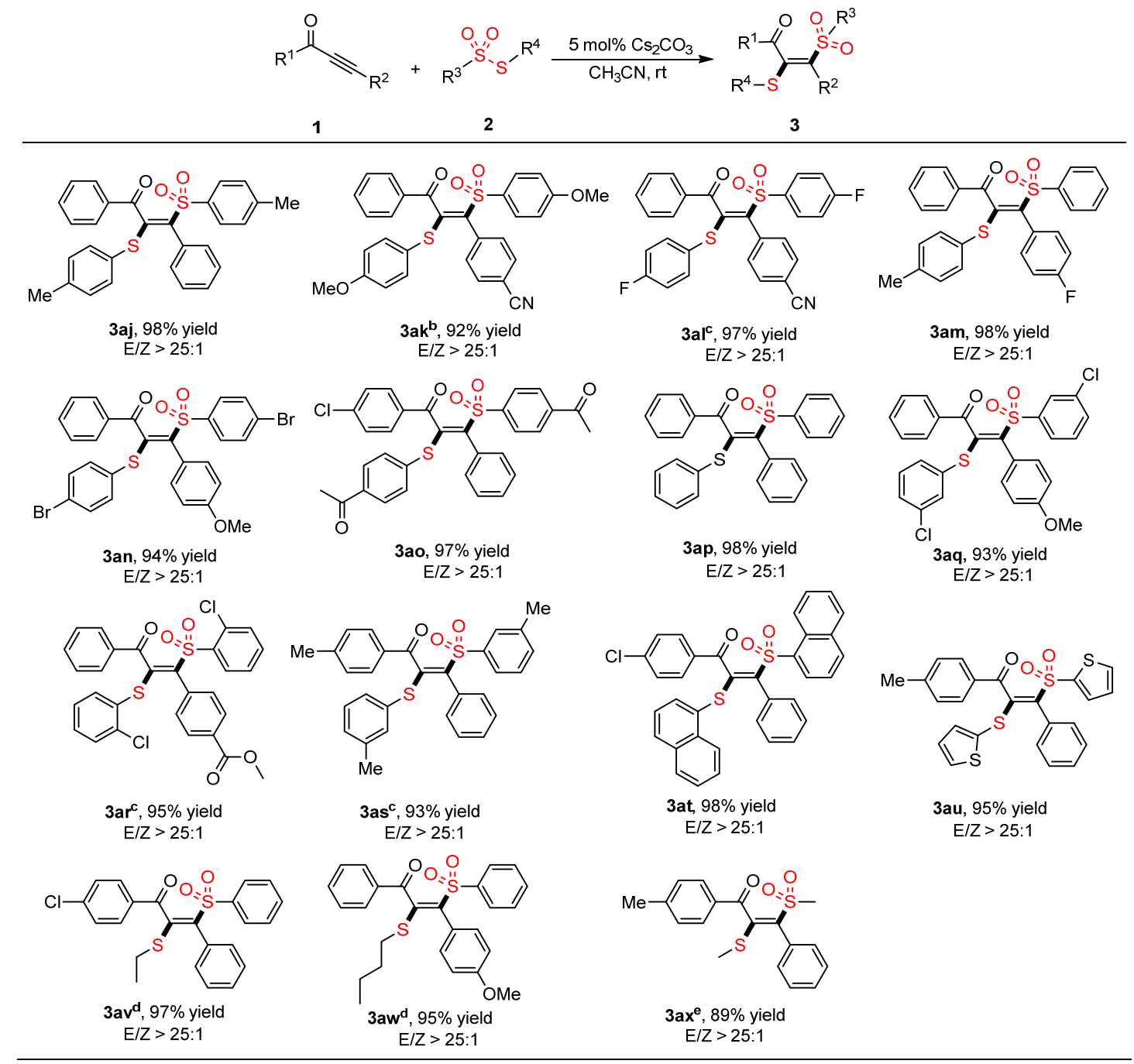

${ }^{a}$ Reaction conditions: 1a $(0.6 \mathrm{mmol}), 2 \mathrm{a}(0.4 \mathrm{mmol}), \mathrm{Cs}_{2} \mathrm{CO}_{3}(5 \mathrm{~mol} \%), \mathrm{CH}_{3} \mathrm{CN}(4.0 \mathrm{~mL}), 8 \mathrm{~h}, \mathrm{rt}$, isolated yield; ${ }^{b} \mathrm{Cs}_{2} \mathrm{CO}_{3}(1 \mathrm{~mol} \%) ;{ }^{c} \mathrm{Cs}_{2} \mathrm{CO}_{3}(2 \mathrm{~mol} \%) ;{ }^{d} \mathrm{Cs}_{2} \mathrm{CO}_{3}(10 \mathrm{~mol} \%) ;{ }^{e} \mathrm{Cs}_{2} \mathrm{CO}_{3}(20 \mathrm{~mol} \%)$.

To gain insight into the reaction mechanism, several control experiments were performed (Scheme 2). The addition of a radical scavenger TEMPO to the reaction has no influence on the formation of the product (eq. 1). Phenylacetylene is a very good reactant in photoredox-catalyzed thiosulfonylation reaction. But under our standard conditions, phenylacetylene cannot react with ynone to give the vicinal 
thiosulfonylation product (eq. 2). Under that catalysis of DBU, thiosulfonate underwent multicomponent reaction with ynone and $\mathrm{H}_{2} \mathrm{O}$ to give vinylsulfone $5 \mathbf{a}$ in $97 \%$ yield (eq. 3). When $\mathrm{D}_{2} \mathrm{O}$ was used instead of $\mathrm{H}_{2} \mathrm{O}$, deuterated product $\mathbf{5 b}$ was achieved in $85 \%$ yield with $99 \%$ Dincorporation. These results indicate that the reaction do not proceed through a radical process.

(1)<smiles>Cc1ccc(C(=O)C#Cc2ccccc2)cc1</smiles>

1a

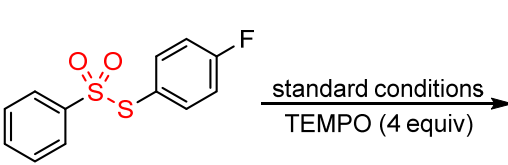

$2 a$

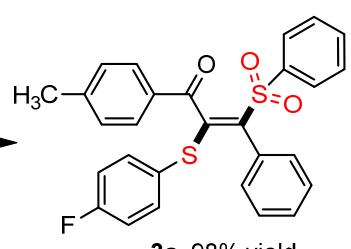

$3 a, 98 \%$ yield

(2)

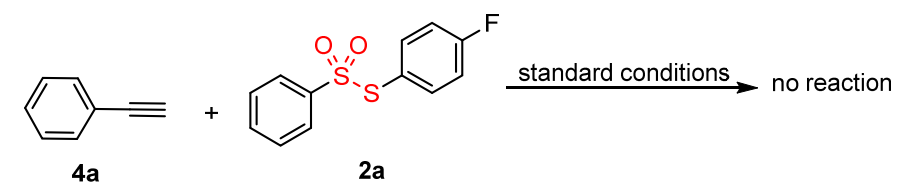

(3)<smiles>Cc1ccc(C(=O)C#Cc2ccccc2)cc1</smiles>

$1 a$<smiles>O=S(=O)(Sc1ccc(F)cc1)c1ccccc1</smiles>

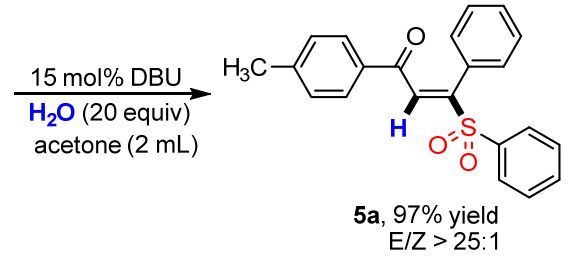

\section{Scheme 2 Control experiments}

Based on the results presented above, a plausible mechanism was proposed in Scheme 3. Base attacks thiosulfonate to generate sulfonyl anion I and species II. Sulfonyl anion I undergoes Michael addition with ynone to give allenoate III, which subsequently attacks the sulfur atom of species II to produce the final product with release of catalyst. In order to minimize the steric repulsion, the adjacent sulfonyl group and the thio group prefer to adopt a trans-conformation, which leads to the formation of $E$-isomer as the major product. 


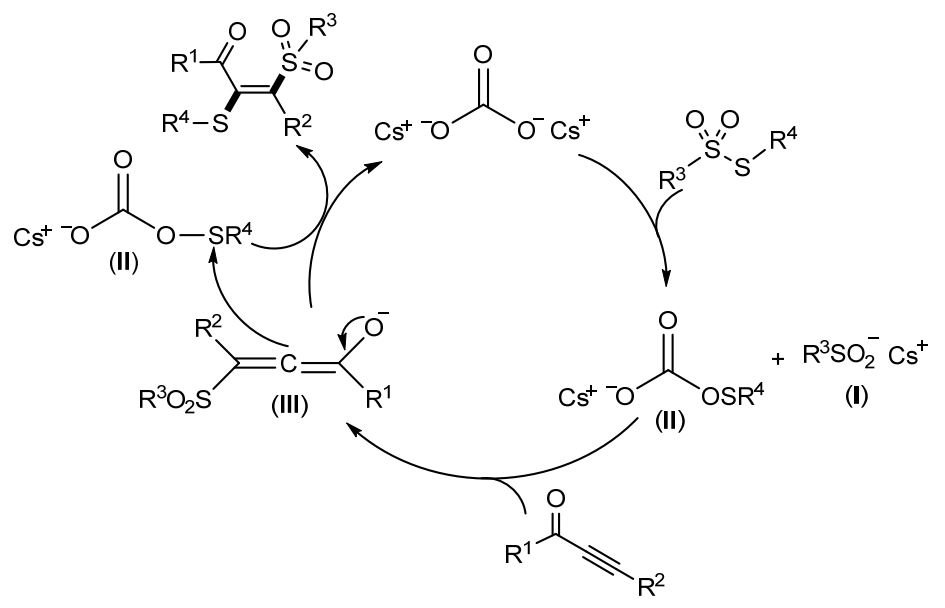

Scheme 3 Proposed mechanism

\section{Conclusions}

In summary, a base-catalyzed difunctionalization of ynones has been described. The metal-free conditions, broad substrate scope, high atomeconomy, excellent reaction yield and stereoselectivity provide a novel method for the synthesis of multifunctionalized vinylsulfones. Further studies on a broader substrate scope and the applications of this method are ongoing in our laboratory.

\section{Conflicts of interest}

There are no conflicts to declare.

\section{Acknowledgements}

Project supported by the National Natural Science Foundation of China (No. 21662029), the Excellent Young Teachers Plan of Bingtuan (Nos. 2017CB001, CZ027203, CZ002203) and the International Cooperation Project of Shihezi University (No. GJHZ201801). 


\section{Notes and references}

1. (a) M.-H. Feng, B.-Q. Tang, S. H. Liang, X.-F. Jiang, Sulfur Containing Scaffolds in Drugs: Synthesis and Application in Medicinal Chemistry, Curr. Top. Med. Chem., 2016, 16, 1200-1216. (b) K. L. Dunbar, D. H. Scharf, A. Litomska, C. Hertweck, Enzymatic Carbon-Sulfur Bond Formation in Natural Product Biosynthesis, Chem. Rev., 2017, 117, 5521-5577. (c) H. Liu, X.-F. Jiang, Transfer of Sulfur: From Simple to Diverse, Chem. Asian J., 2013, 8, 2546-2563. (d) H. Mori, Y. Nishihara, Low-bandgap semiconducting polymers based on sulfur-containing phenacene-type molecules for transistor and solar cell applications, Polym. J., 2018, 50, 615-625.

2. (a) S. Y. Woo, J. H. Kim, M. K. Moon, S. H. Han, S. K. Yeon, J. W. Choi, B. K. Jang, H. J. Song, Y. G. Kang, J. W. Kim, J. Lee, D. J. Kim, O. Hwang, K. D. Park, Discovery of Vinyl Sulfones as a Novel Class of Neuroprotective Agents toward Parkinson's Disease Therapy, J. Med. Chem., 2014, 57, 1473-1487. (b) M. S. Vedula, A. B. Pulipaka, C. Venna, V. K. Chintakunta, S. Jinnapally, V. A. Kattuboina, R. K. Vallakati, V. Basetti, V. Akella, S. Rajgopal, A. K. Reka, S. K. Teepireddy, P. K. Mamnoor, R. Rajagopalan, G. Bulusu, A. Khandelwal, V. V. Upreti, S. R. Mamidi, New styryl sulfones as anticancer agents, Eur. J. Med. Chem., 2003, 38, 811-824. (c) J. Morales-Sanfrutos, J. Lopez-Jaramillo, M. Ortega-Muñoz, A. Megia-Fernandez, F. Perez-Balderas, F. Hernandez-Mateo, F. Santoyo-Gonzalez, Vinyl sulfone: a versatile function for simple bioconjugation and immobilization, Org. Biomol. Chem., 2010, 8, 667-675.

3. (a) G.-Y.-S. Qiu, K.-D. Zhou, L. Gao, J. Wu, Insertion of sulfur dioxide via a radical process: an efficient route to sulfonyl compounds, Org. Chem. Front., 2018, 5, 691-705. (b) K. Hofman, N.-W. Liu, G. Manolikakes, Radicals and Sulfur Dioxide: A Versatile Combination for the Construction of Sulfonyl-Containing Molecules, Chem. Eur. J., 2018, 24, 11852-11863. (c) D. Joseph, M. A. Idris, J. Chen, S. Lee, Recent Advances in the Catalytic Synthesis of Arylsulfonyl Compounds, ACS Catal., 2021, 11, 4169-4204.

4. (a) S. Chodroff, W. F. Whitmore, The Preparation of unsaturated sulfones by condensation reactions, J. Am. Chem. Soc., 1950, 72, 1073-1076. (b) D. A. R. Happer; B. E. Steenson, Preparation of $\alpha, \beta$-unsaturated sulfones by the Knoevenagel method, Synthesis, 1980, 806-807.

5. (a) M. He, A. K. Ghosh, B. Zajc, Julia Olefination as a General Route to Phenyl ( $\alpha$-Fluoro)vinyl Sulfones, Synlett, 2008, 999-1004. (b) I. C. Popoff, J. L. Dever, G. R. Leader, $\alpha, \beta$-Unsaturated sulfones via phosphonate carbanions, J. Org. Chem., 1969, 34, 1128-1130.

6. (a) N. S. Simpkins, The chemistry of vinyl sulphones, Tetrahedron, 1990, 46, 6951-6984. (b) X. Huang, D.-H. Duan, W.-X. Zheng, Studies on Hydrozirconation of 1-Alkynyl Sulfoxides or Sulfones and the Application for the Synthesis of Stereodefined Vinyl Sulfoxides or Sulfones, $J$. Org. Chem., 2003, 68, 1958-1963.

7. (a) O. Reiser, Shining Light on Copper: Unique Opportunities for Visible-Light-Catalyzed Atom Transfer Radical Addition Reactions and Related Processes, Acc. Chem. Res., 2016, 49, 1990-1996.

(b) C. K. Prier, D. A. Rankic, D. W. C. MacMillan, Visible Light Photoredox Catalysis with Transition Metal Complexes: Applications in Organic Synthesis, Chem. Rev., 2013, 113, 5322-5363.

(c) T. Besset, T. Poisson, X. Pannecoucke, Direct Vicinal Difunctionalization of Alkynes: An Efficient Approach Towards the Synthesis of Highly Functionalized Fluorinated Alkenes, Eur. J. Org. Chem., 2015, 2015, 2765-2789.

8. (a) Y.-J. Zhang, E. Vessally, Direct halosulfonylation of alkynes: an overview, RSC Adv., 2021, 11, 33447-33460. (b) P. Chakrasali, K. Kim, Y.-S. Jung, H. Kim, S. B. Han, Visible-Light-Mediated Photoredox-Catalyzed Regio- and Stereoselective Chlorosulfonylation of Alkynes, Org. Lett., 2018, 
20, 7509-7513. (c) M. Alkan-Zambada, X.-L. Hu, Cu-Catalyzed Photoredox Chlorosulfonation of Alkenes and Alkynes, J. Org. Chem., 2019, 84, 4525-4533. (d) K. Zeng, L. Chen, Y. Chen, Y.-P. Liu, Y.-B. Zhou, C.-T. Au, S.-F. Yin, Iron(III) Chloride-Mediated Regio- and Stereoselective Chlorosulfonylation of Alkynes and Alkenes with Sodium Sulfinates, Adv. Synth. Catal., 2017, 359, 841-847. (e) R. Kumar, V. Dwivedi, M. Sridhar Reddy, Metal-Free Iodosulfonylation of Internal Alkynes: Stereodefined Access to Tetrasubstituted Olefins, Adv. Synth. Catal., 2017, 359, $2847-$ 2856. (f) P. Zhou, Y.-P. Pan, H. Tan, W.-B. Liu, $\mathrm{I}_{2}-\mathrm{DMSO}-\mathrm{H}_{2} \mathrm{O}$ : A Metal-Free Combination System for the Oxidative Addition of Alkynes to Access (E)- $\alpha$-Iodo- $\beta$-methylsulfonylalkenes, J. Org. Chem., 2019, 84, 15662-15668. (g) Y. Gao, W.-Q. Wu, Y.-B. Huang, K.-F. Huang, H.-F. Jiang, NBSpromoted halosulfonylation of terminal alkynes: highly regio- and stereoselective synthesis of (E)B-halo vinylsulfones, Org. Chem. Front., 2014, 1, 361-364.

9. (a) S.-L. Huang, Z.-L. Chen, H. Mao, F.-L. Hu, D.-M. Li, Y. Tan, F.-Q. Yang, W.-L. Qin, Metalfree difunctionalization of alkynes to access tetrasubstituted olefins through spontaneous selenosulfonylation of vinylidene ortho-quinone methide (VQM), Org. Biomol. Chem., 2019, 17, 1121-1129. (b) K. Sun, Z.-D. Shi, Z.-H. Liu, B.-X. Luan, J.-L. Zhu, Y.-R. Xue, Synthesis of (E)-pSelenovinyl Sulfones through a Multicomponent Regio- and Stereospecific Selenosulfonation of Alkynes with Insertion of Sulfur Dioxide, Org. Lett., 2018, 20, 6687-6690. (c) K. Sun, X. Wang, F.F. Fu, C. Zhang, Y. Chen, L. Liu, Metal-free selenosulfonylation of alkynes: rapid access to $\beta$ (seleno)vinyl sulfones via a cationic-species-induced pathway, Green Chem., 2017, 19, 1490-1493. (d) Y. Liu, G.-F. Zheng, Q. Zhang, Y. Li, Q. Zhang, Copper-Catalyzed Three Component Regio- and Stereospecific Selenosulfonation of Alkynes: Synthesis of (E)- $\beta$-Selenovinyl Sulfones, J. Org. Chem., 2017, 82, 2269-2275.

10. (a) M. Y. Ansari, S. Swarnkar, A. Kumar, Stereoselective aminosulfonylation of alkynes: an approach to access (Z)- $\beta$-amino vinylsulfones, Chem. Commun., 2020, 56, 9561-9564. (b) J.-C. Li, Z.-P. Yang, R. Guo, M.-Y. Jin, J. Wang, Atom-Economical and Stereoselective Difunctionalization of Electron-Withdrawing Alkynes with N-Trifluoromethylthiophthalimide, Asian J. Org. Chem., 2018, 7, 1784-1787. (c) Y.-Q. Ning, Q.-H. Ji, P.-Q. Liao, E. A. Anderson, X.-H. Bi, Silver-Catalyzed Stereoselective Aminosulfonylation of Alkynes, Angew. Chem. Int. Ed., 2017, 56, 13805-13808.

11. (a) H. Fu, J.-Q. Shang, T. Yang, Y.-H. Shen, C.-Z. Gao, Y.-M. Li, Copper-Catalyzed Decarboxylative Disulfonylation of Alkynyl Carboxylic Acids with Sulfinic Acids, Org. Lett., 2018, 20, 489-492. (b) Z.-H. Liu, L. Yang, K.-N. Zhang, W.-J. Chen, T. Yu, L.-X. Wang, W. Gao, B. Tang, Copper-Catalyzed Disulfonation of Terminal Alkynes with Sodium Arylsulfinates, Org. Lett., 2020, 22, 2081-2086. (c) Y. Wang, K.-S. Tang, Z.-H. Liu, Y.-Q. Ning, Disulfonation of terminal alkynes for 1,2-bisulfonylethenes, Chem. Commun., 2020, 56, 13141-13144. (d) H. Fu, J.-Q. Shang, T. Yang, Y.-H. Shen, C.-Z. Gao, Y.-M. Li, Copper-Catalyzed Decarboxylative Disulfonylation of Alkynyl Carboxylic Acids with Sulfinic Acids, Org. Lett., 2018, 20, 489-492.

12. (a) M.-M Zhang, X.-H. Zeng, Metal-Free Radical Thiocyanatosulfonation of Terminal Alkynes in Aqueous Medium, Org. Lett., 2021, 23, 3326-3330. (b) L.-H. Lu, S.-J. Zhou, W.-B. He, W. Xia, P. Chen, X.-Y. Yu, X.-H. Xu, W.-M. He, Metal-free difunctionalization of alkynes leading to alkenyl dithiocyanates and alkenyl diselenocyanates at room temperature, Org. Biomol. Chem., 2018, 16, 9064-9068.

13. (a) A. García-Domínguez, S. Müller, C. Nevado, Nickel-Catalyzed Intermolecular Carbosulfonylation of Alkynes via Sulfonyl Radicals, Angew. Chem. Int. Ed., 2017, 56, 9949-9952.

(b) Y.-C. Xiang, Y.-W. Li, Y.-Y. Kuang, J. Wu, Stereoselective Vicinal Difunctionalization of 
Alkynes through a Three-Component Reaction of Alkynes, Sodium Sulfinates, and Togni Reagent, Adv. Synth. Catal., 2017, 359, 2605-2609.

14. A. K. Sahoo, A. Dahiya, B. Das, A. Behera, B. K. Patel, Visible-Light-Mediated Difunctionalization of Alkynes: Synthesis of $\beta$-Substituted Vinylsulfones Using O- and S-Centered Nucleophiles, J. Org. Chem., 2021, 86, 11968-11986.

15. (a) H.-Y. Li, Z.-R. Cheng, C.-H. Tung, Z.-H. Xu, Atom Transfer Radical Addition to Alkynes and Enynes: A Versatile Gold/Photoredox Approach to Thio-Functionalized Vinylsulfones, ACS Catal., 2018, 8, 8237-8243. (b) K.-M. Mao, M.-W. Bian, L. Dai, J.-H. Zhang, Q.-Y. Yu, C. Wang, L.-C. Rong, Metal-Free Radical Annulation of Oxygen-Containing 1,7-Enynes: ConfigurationSelective Synthesis of (E)-3-((Arylsulfonyl)methyl)-4-Substituted Arylidenechromene Derivatives, Org. Lett., 2021, 23, 218-224. (c) H.-Y. Li, C.-C. Shan, C.-H. Tung, Z.-H. Xu, Dual gold and photoredox catalysis: visible light-mediated intermolecular atom transfer thiosulfonylation of alkenes, Chem. Sci., 2017, 8, 2610-2615. (d) S. Huang, H.-Y. Li, T. Xie, F. Wei, C.-H. Tung, Z.-H. $\mathrm{Xu}$, Scandium-catalyzed electrophilic alkene difunctionalization: regioselective synthesis of thiosulfone derivatives, Org. Chem. Front., 2019, 6, 1663-1666.

16. (a) Z.-Y. Peng, H.-L. Yin, H. Zhang, T.-Z. Jia, Regio- and Stereoselective Photoredox-Catalyzed Atom Transfer Radical Addition of Thiosulfonates to Aryl Alkynes, Org. Lett., 2020, 22, 5885-5889. (b) X. Zhou, Z.-Y. Peng, P. G. Wang, Q.-C. Liu, T.-Z. Jia, Atom Transfer Radical Addition to Styrenes with Thiosulfonates Enabled by Synergetic Copper/Photoredox Catalysis, Org. Lett., 2021, 23, 1054-1059.

17. R. J. Reddy, A. H. Kumari, J. J. Kumar, J. B. Nanubolu, $\mathrm{Cs}_{2} \mathrm{CO}_{3}$-Mediated Vicinal Thiosulfonylation of 1,1-Dibromo-1-Alkenes with Thiosulfonates: An Expedient Synthesis of (E)1,2-Thiosulfonylethenes, Adv. Synth. Catal., 2019, 361, 1587-1591.

18. (a) Y. An, F. Zhang, G.-F. Du, Z.-H. Cai, L. He, Construction of 6H-benzo[c]thiochromenes via a tandem reaction of arynes with thionoesters, Org. Chem. Front., 2021, 8, 6979-6984. (b) Z.-S. Cong, Y.-G. Li, G.-F. Du, C.-Z. Gu, B. Dai, L. He, N-Heterocyclic carbene-catalyzed sulfa-Michael addition of enals, Chem. Commun., 2017, 53, 13129-13132. (c) L. He, H. Guo, Y.-Z. Li, G.-F. Du, B. Dai, N-Heterocyclic carbene-catalyzed formal cross-coupling reaction of $\alpha$-haloenals with thiols: organocatalytic construction of sp $^{2}$ carbon-sulfur bonds, Chem. Commun., 2014, 50, 3719-3721. (d) J.-Y. Luo, M.-Z. Lin, L.-F. Wu, Z.-H. Cai, L. He, G.-F. Du, The organocatalytic synthesis of perfluorophenylsulfides via the thiolation of trimethyl(perfluorophenyl)silanes and thiosulfonates, Org. Biomol. Chem., 2021, 19, 9237-9241.

19. The CCDC number of product 3ap is 2153291. 